\title{
A ELT E OS PRINCÍPIOS PEDAGÓGICOS PARA UMA DRAMATURGIA COLABORATIVA
}

\author{
Rafael Ary \\ Doutor em Artes da Cena (UNICAMP) \\ Dramaturgo, diretor e ator. \\ E-mail: rafaelary@ymail.com
}

Este artigo discorre sobre os princípios pedagógicos da Escola Livre de Teatro de Santo André (ELT) e sua importância para a conformação da prática de uma dramaturgia colaborativa, cuja influência é perceptível nos processos criativos em grupos de teatro da cidade de São Paulo e no projeto pedagógico do curso de dramaturgia da SP Escola de Teatro.

Palavras-chave

Dramaturgia. Processo Colaborativo. Pedagogia Teatral.
This article examines the pedagogical principles of the Escola Livre de Teatro de Santo André (ELT) and its importance for the creation and practice of collaborative playwriting. The influence of this kind of creation is visible in the creative process in theater groups from the city of São Paulo and in the pedagogical project of the course of the playwriting in the SP Escola de Teatro.
Keywords

Playwriting. Collaborative Process. Theatrical Pedagogy. 
A Escola Livre de Teatro de Santo André foi criada em 1990, como resultado das reivindicações da classe artística da cidade por um centro de formação voltado aos seus interesses. A diretora de teatro e pesquisadora Maria Thais foi convidada por Celso Frateschi, secretário de cultura na época, para estruturar o projeto da escola em sua fase inicial, mais especificamente entre 1990 e 1993.

A pesquisadora Vilma Campos dos Santos Leite expõe, no fragmento abaixo, a passagem de Maria Thais por reconhecidas escolas de teatro do Brasil, antes de aceitar o desafio de capitanear a Escola Livre de Teatro (ELT) em seu princípio.

A formulação de um projeto piloto para a criação daquela que passou a ser a ELT, bem como o primeiro biênio da sua coordenação, coube à Maria Thais Lima Santos, já com histórico de formação e prática artística, tendo atuado como professora de teatro no decorrer da década de 1980, em escolas como Macunaíma, em São Paulo, e o Centro de Artes de Laranjeiras (CAL) no Rio de Janeiro (Leite, 2010, p. 3-4).

Atualmente, a ELT possui oito núcleos de pesquisa. Um núcleo de pesquisa para a formação do ator, com duração de quatro anos para cada turma. Além desse, existem mais sete núcleos de pesquisa teatral, com duração de um ano cada. Entre esses núcleos, com duração de um ano, está o de dramaturgia. Essa estrutura se mantém mais ou menos do mesmo modo desde a criação da ELT. Um curso principal de formação de atores com os núcleos girando ao redor, dando o suporte necessário e promovendo a diversidade estética para os aprendizes de atuação.

Uma das características mais marcantes da ELT tem a ver com uma palavra que compõe seu título: livre. Até o presente, nunca houve um plano pedagógico contínuo na escola, no que diz respeito a um estilo de atuação preponderante, como se dá em um estúdio, por exemplo, algo que demarque um território exclusivo e contínuo em sua história. Cada turma, orientada por formadores distintos, encaminha seus projetos de acordo com as necessidades que se apresentam.

O dramaturgo e diretor Antônio Rogério Toscano, atual coordenador da ELT, aponta estas características na citação adiante:

Durante o caminho da criação, o in-
teresse pedagógico concentra-se em
instilar inquietação criativa nos apren-
dizes/artistas (nunca alunos - aluno,
aquele que não tem luz própria), sob
condições experimentais, para que
floresça então uma arte comprometi-
da, atuante e radicalmente viva - que
responda à sensibilidade concreta do
mundo que a cerca (Toscano, 2004, p.
16).

As experiências artísticas que marcaram a história da ELT estão ligadas aos mestres que passaram por lá. Dessa maneira, no que diz respeito ao campo da dramaturgia, a presença de Luís Alberto de Abreu, nos primórdios da escola, foi fundamental para estabelecer a dramaturgia colaborativa como prática pedagógica na ELT.

Abreu introduziu a noção de processo colaborativo na escola, de forma a valorizar a função do dramaturgo, sem apartá-lo da sala de ensaio. A partir dali, na ELT, ficou patente a necessidade e importância da função do dramaturgo para uma composição teatral rica em camadas poéticas.

A chegada de Abreu na ELT serviu também para realizar sua aspiração de ter um trabalho de formação mais contínuo, diferentemente do que ele estava experienciando até aquele momento na cidade de São Paulo. 
Abreu assinala, no trecho de uma entrevista que veremos a seguir, a importância da ELT para o desenvolvimento de sua atividade como dramaturgo e formador.

Nesse momento em que a escola foi fundada eu estava voltando aqui pro $A B C$. Eu já estava morando aqui, mas voltando, quer dizer 'interesse de me fixar mais no ABC'. [...] Quando a Thais entrou em contato comigo para um curso de dramaturgia na escola, eu falei 'eu já estou cansado das oficinas, do tipo de encaminhamento da dramaturgia que tem em São Paulo'. Eu já tinha trabalhado três anos na Oficina Estadual Três Rios e tinha trabalhado no CPT (Centro de Pesquisa Teatral) no SESC com o Antunes Filho. Era uma sucessão de oficinas. Eu falei que estava mais a fim de um trabalho que eu pudesse dar continuidade mesmo. Que o meu trabalho como dramaturgo estivesse mais perto da cena (Leite, 2010, p. 98-99).

O desejo de Luís Alberto Abreu de realizar um processo de formação continuado pode ser visto como um sintoma da falta de espaços de ensino em dramaturgia no Brasil. A consolidação das práticas de ensino de dramaturgia na ELT e na SP Escola de Teatro, realizadas de maneira distinta em cada local, está intimamente ligada à inquietação desse dramaturgo, direta e indiretamente.

Para citar um exemplo da importância de Abreu para o desenvolvimento da dramaturgia em São Paulo, Marici Salomão, coordenadora do curso de dramaturgia da SP Escola de Teatro e do Núcleo de Dramaturgia do Sesi-British Council, considera Abreu como seu mestre formador. Hoje, Marici é responsável pelo único curso profissionalizante de dramaturgia do país, além de também gerenciar o Núcleo do Sesi-British Council, cuja relevância e alcance já foram expostos neste trabalho.

A trajetória artística de Marici Salomão, tal- vez, seja o exemplo mais evidente da influência de Abreu, por meio de seus processos educacionais, mas não é o único. Os dramaturgos: Cássio Pires, Lucienne Guedes, Alessandro Toller, entre outros, foram aprendizes de Luís Alberto de Abreu. Todos os supracitados possuem destaque como formadores teatrais na atualidade.

Abreu, no excerto seguinte, apresenta os motivos de seu investimento na formação de novos dramaturgos e os resultados alcançados nas últimas décadas:

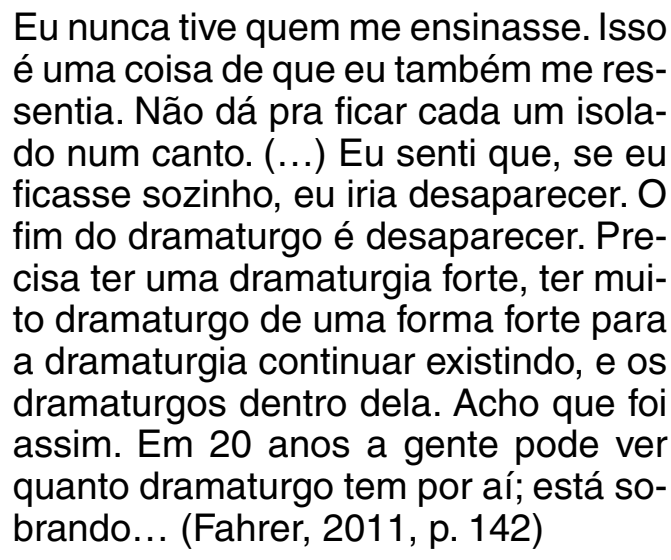

Abreu e outros artistas aproveitaram a liberdade curricular da ELT para aprimorar os modos de criação e, por conseguinte, de ensino do teatro, por meio da convicção de que a arte se ensina criando. E quem cria é artista, portanto, artista deve formar artistas, caracterizando uma relação secular que envolve a noção de mestre e aprendiz.

$\mathrm{Na}$ ELT, como ficou evidente até o momento, os professores e estudantes são chamados de mestres e aprendizes, respectivamente, na tentativa de aproximar a experiência de ensino da antiga relação entre o mestre artesão e o aprendiz, se distanciando, assim, de uma nomenclatura que pressuponha modelos 
enrijecidos e desnecessariamente hierárquicos. Por consequência, a ELT fomenta:

A pedagogia livre, aberta e transitiva, em que o poder mágico dos saberes não está dado de antemão a nenhum feiticeiro - ele é criado no dia a dia, após as crises cotidianas do trabalho com a poesia cênica, quando o jovem artista torna-se tão responsável pelo processo quanto seu orientador e a horizontalidade desta relação espelha o jogo ancestral vivido entre mestre e discípulo (Toscano, 2004, p. 16).

Os princípios da prática pedagógica da ELT priorizam a formação dos aprendizes por artistas, sem menosprezar, com isso, os estudiosos da pedagogia do teatro e teóricos de todos os tipos que não possuam uma carreira artística. No trecho a seguir, é possível observar os acordos éticos realizados entre a escola e o aprendiz que deseja frequentá-la, assim como é possível notar os pressupostos teóricos que embasam o projeto pedagógico da ELT.

O aprendiz tem a seu favor o princípio de autonomia paulofreireano, que vem sendo experimentado e amadurecido. Por um lado, há o propósito de estimular o exercício consciente da estética nas bases de uma criação e de um relacionamento éticos. Por outro, esse pressuposto não dispensa o fato de que a autonomia não é delegada, é uma conquista que se alcança com empenho próprio e compromisso em relação às tarefas coletivas. Como a Escola não tem um modelo tradicional de avaliação (por testes e instrumentos de aferição quantitativa do conhecimento), o fundamental é que o aprendiz esteja comprometido com os processos. O excesso de faltas, portanto, é fator preponderante para seu desligamento. Mais que a expressão do talento - sempre bem-vindo, mas não regente dos processos - é a aderência verdadeira ao dia a dia da Escola o que conta (Escola Livre De Teatro, 2010, p. 43).
Quando observamos com atenção, é possível perceber as semelhanças entre as diretrizes do processo colaborativo e do projeto pedagógico da ELT. Seriam estas:

- A atenção destinada ao processo, dedicando menos importância ao resultado espetacular.

- A relação horizontal entre o mestre e o aprendiz, incentivando a mútua cooperação para empreender um projeto de pesquisa estética. Visando apropriar o aprendiz dos elementos elaborados durante o processo criativo, tendo em vista o aprimoramento de suas capacidades como artista.

Dessa maneira, o processo colaborativo se tornou uma constante na ELT, assim como uma abordagem metodológica amplamente utilizada pelos grupos de teatro de São Paulo e, ulteriormente, do Brasil. Os mestres que passaram pela ELT levaram o processo colaborativo consigo para universidades, escolas profissionalizantes e cursos livres.

Antônio Rogério Toscano aponta a importância do processo colaborativo para o teatro brasileiro e sua filiação à ELT:

Por esta época, a presença de processos colaborativos reverberava experiências gestadas há alguns anos na própria Escola, quando algumas parcerias artísticas fundamentais para o Teatro Brasileiro Contemporâneo se fortaleceram ali, como, por exemplo, os primeiros projetos do Teatro da Vertigem, que contaram com a participação de Antônio Araújo, de Sérgio de Carvalho, de Lucienne Guedes e do próprio Abreu, todos professores dos primeiros tempos (Escola Livre De Teatro, 2010, p. 49). 
Dois aspectos relevantes para o desenvolvimento da ideia central deste artigo estão presentes no projeto pedagógico da ELT:

- A utilização do processo colaborativo como ferramenta educacional.

- E a valorização da dramaturgia, e do ofício de dramaturgo, por consequência, materializada na proposição de um núcleo de dramaturgia, no primeiro caso, e de um curso regular de dramaturgia, no segundo caso.

A influência que os mestres exerceram, nos primórdios e posteriormente, ao propor seus procedimentos criativos, configurou a grade curricular da escola, turma a turma. Suas contribuições deixaram marcas indeléveis na maneira de enxergar o ensino teatral na ELT.

A pedagogia colaborativa foi, dessa maneira, talvez a única constante durante todo o período. Daí por diante, cada projeto artístico conduzia o processo em busca de reconhecer as necessidades técnicas e pedagógicas que surgiam dessa fricção entre a prática colaborativa e a temática proposta pelo mestre aos aprendizes.

Kil Abreu, que foi coordenador da ELT em duas ocasiões, salienta o funcionamento da escola com relação aos mestres convidados para encaminhar os processos criativos. Ele diz:

[...] o que acontece na ELT é que a escola não tem grade curricular fixa e não trabalha, em princípio, com a ideia de uma cobertura técnica ordenada na formação do intérprete, do diretor, do dramaturgo, etc. A importância das técnicas, claro, não precisa ser advogada, são instrumentos necessários a qualquer arte. Mas aqui a técnica é chamada sempre em função de um projeto artístico, e de um artista. Então, por exemplo, não convidamos para o lugar de mestre na Escola alguém para dar aulas de direção, mas a Cibele Forjaz, que tem naquele momento da sua vida artística o interesse em experimentar um determinado modo de fazer teatro. Não será outro o repertório, será este. Então a técnica entra a serviço de uma poética, não está alienada desta (Abreu, 2006, p. 49).

Luís Alberto de Abreu foi essencial na proposição de um olhar cenicamente inclusivo sobre a dramaturgia. Apesar de não haver um propósito de se formar dramaturgos na ELT, pois a prioridade da escola é a formação do ator, o que é feito sem preocupações acadêmicas, com títulos ou registros profissionais que permita o acesso ao mercado de professores licenciados em escolas de ensino fundamental, por exemplo.

A ELT não tem como preocupação, desde sua fundação, se adequar às exigências do Ministério da Educação, dessa forma, pode ostentar a palavra livre em seu nome de forma coerente com suas práticas. Por outro lado, a escola também não pode conceder diplomas de nenhuma natureza. É o preço a ser pago pela liberdade curricular.

De todo modo, essas características não parecem incomodar os mestres e os aprendizes, afinal, o curso de formação de atores possui a duração de quatro anos, sem que haja nenhuma certificação ao final. Quem procura 
a ELT para estudar teatro está em busca da experiência artística proporcionada pela escola e seus mestres. "E ninguém permanece por inércia à espera de um diploma ou de um desnecessário DRT. Fica o pesquisador, o colaborador e o criador autênticos" (Escola Livre De Teatro, 2010, p.47).

A ELT, a partir dessa forma de proceder, se afasta dos padrões de ensino do teatro na atualidade. Tendo em vista tais características, atentemos para a descrição encontrada na página virtual da ELT sobre os tipos de escola teatrais existentes no nosso país.

Basicamente, são duas as espécies de escolas teatrais encontráveis no Brasil: ou adotam o modelo acadêmico clássico, que equilibra formação teórica e prática segundo uma perspectiva mais histórica do que estética e mais passiva que ativa, onde os professores muito frequentemente não mais exercem atividades artísticas, ou têm como objetivo apenas fornecer certificados profissionais e fabricar atores descartáveis, conquistados com a ilusão do trabalho na televisão. $O$ intuito básico da proposta da Escola Livre era desde o princípio - e se mantém assim até hoje -, conseguir a mobilidade de uma oficina cultural sem perder de vista a perspectiva formativa do aluno. Cuidar de seu crescimento artístico e instrumentalizá-lo em termos de conhecimento eatral sem amarrá-lo a obrigações curriculares pré-fixadas. ${ }^{1}$

Apesar de a citação acima ser questionável, no que diz respeito à descrição de muitos cursos de teatro no Brasil, a proposta de ensino da ELT, principalmente no que tange à prática artística como procedimento de ensino, está presente, em maior ou menor intensidade, em diversos cursos superiores e profissionalizantes de teatro, como nos da Universidade Estadual de Campinas (Unicamp) e Universidade de São Paulo (USP), por exemplo.

O diretor Antônio Araújo destaca, na citação a seguir, o caráter vanguardista da ELT, no que se refere ao uso do processo colaborativo como modo de ensino. Conforme Antônio Araújo:

[...] aconteceu uma coisa muito bacana, que foi a junção do Núcleo de Dramaturgia e o Núcleo de Direção. E eu acho que tem a ver com a parceria com o Abreu já da primeira leva da escola. O Abreu foi meu professor no CPT de dramaturgia e depois numa relação não mais de professor e de aluno, a gente trabalhou no que culminou no Livro de Jó. Eu sinto que nessa retoma$\mathrm{da}$, de um namoro, da gente dizer em determinado momento vamos cruzar esses dois núcleos e fazer uma coisa mais integrada? Acho que de novo tem a ver com esse tipo de maleabilidade. Penso de novo nesse caráter de vanguarda e antecipador da ELT. Tempos depois, eu convido o Abreu para ir pra USP e a gente desenvolve uma experiência de processo colaborativo que se mantém até hoje (Leite, 2010, p. 224).

Foi na ELT que, pela primeira vez, se utilizou a expressão processo colaborativo em um contexto pedagógico, como ferramenta de ensino do teatro. Seu uso se consolidou na escola por meio, principalmente, das presenças de Luís Alberto de Abreu e Antônio Araújo.

O projeto pedagógico da ELT serviu de influência para a SP Escola de Teatro na conformação do seu projeto. Por consequência, é possível observar esses princípios pedagógicos no funcionamento dos cursos regulares, o que inclui o curso de dramaturgia.

O processo colaborativo, como ferramenta pedagógica, é o elo mais significativo que une a ELT e a SP Escola de Teatro. Em conformidade com a atriz e pesquisadora Juliana Monteiro:

\footnotetext{
$\overline{1}$ Disponível em: <http://www.escolalivredeteatro.blogspot.com.br/p/historico_1.html>. Acesso em: 28 mar. 2016.
} 
Foi na ELT, por exemplo, que se consolidou a parceria entre o dramaturgo Luís Alberto de Abreu e o encenador Antônio Araújo, da qual surgiu o importante espetáculo dos anos 1990: O Livro de Jó. Foi lá que, pela primeira vez, teorizou-se sobre uma prática hoje amplamente difundida no teatro paulista, o "processo colaborativo", que já vinha sendo exercitado com as turmas de aprendizes na Escola e que teve registro - já reconhecido publicamente pela imprensa como precursor do debate publicado nos Cadernos da ELT (Escola Livre De Teatro, 2010, p. 38).

O registro precursor do debate, citado na passagem acima, diz respeito ao artigo de Luís Alberto de Abreu, intitulado: Processo Colaborativo: Relato e Reflexão sobre uma Experiência de Criação, cuja repercussão foi eminente e proporcionou ao processo colaborativo uma conformação conceitual que era necessária. Em relação à influência do projeto pedagógico da ELT no projeto da SP Escola de Teatro, Ivam Cabral, diretor executivo da SP Escola de Teatro, assinala:

(Maria) Thais criou, ao lado de Celso Frateschi, em 1990, a ELT que, alguns anos, tornou-se referência no ensino teatral brasileiro. E, claro, nosso Projeto Político-Pedagógico foi todo inspirado - direta e profundamente - por esta estrutura e metodologia. ${ }^{2}$

Interessante notar como os procedimentos de formação da ELT são descritos de forma semelhante aos procedimentos de criação dos grupos de teatro que praticam o processo colaborativo, como por exemplo as descrições de processos realizados pelo Teatro da Vertigem (SP), disponíveis em diversos artigos, dissertações e teses, entre outros.

Veremos, no excerto abaixo, uma definição dos processos de criação com intuito formativo da ELT. A partir dessa descrição, é possível perceber, por exemplo, o procedimento, comum aos processos colaborativos dos grupos de teatro, que propõe a cena como o argumento mais importante de um processo criativo. A permeabilidade entre as funções é outro aspecto destacado no excerto. Isto posto, Antônio Rogério Toscano afirma que:

Os processos criativos são filtrados pela experiência (a cena é o juiz do jogo, que define quais são os próximos passos). E sempre são eles que criam, entre si, e de maneira fluida, articulações orgânicas. Os diferentes grupos de trabalho se contaminam e se influenciam mutuamente e, com isso, formam conexões vivas por onde circulam, livres, as informações. Ou seja, esta criação, sem métodos precedentes e preestabelecidos, deve estar sempre articulada por um rigoroso processo de reflexão, que busca permanentemente novos nortes, apropriados para cada nova etapa. E esses nortes são fixados apenas momentaneamente, e depois remodelados pelo coletivo (Toscano, 2004, p. 17).

O núcleo de dramaturgia da ELT não se configura como um curso profissionalizante, nem mesmo formativo, se compararmos com o modelo proposto pela ELT para a formação do ator. $O$ núcleo de dramaturgia pode ser descrito como uma extensa oficina que gira em torno, como auxiliar, do processo de formação dos atores.

Nas primeiras turmas da ELT, o núcleo de dramaturgia tinha certa independência dos demais, porém, com o passar do tempo e das experiências, se percebeu que os núcleos deveriam trabalhar em consonância, principalmente no que diz respeito aos núcleos de formação de atores e direção, como ficou

\footnotetext{
2 Ivam Cabral. Disponível em: <http://www.spescoladeteatro.org.br/colunistas/ivam-61.php\#coluna>. Acesso em: 28 mar. 2016.
} 
notório na citação de Antônio Araújo, alguns parágrafos acima, quando ele fala da junção dos núcleos de dramaturgia e direção. A seguir, observar-se-ão as diretrizes de funcionamento do núcleo de dramaturgia da ELT na atualidade.

Objetivo geral: Criar um espaço de experimentação de escrita dramática e pós-dramática a partir de diversos estímulos literários, visuais ou de observação do cotidiano. Objetivos específicos: Ampliar o conhecimento sobre dramaturgia a partir da leitura de artigos sobre dramaturgia e peças teatrais; Estimular a leitura dos textos desenvolvidos pelos aprendizes durante o processo dentro de um fórum permanente de discussão sobre os procedimentos da escrita; Organizar a construção de um blog contendo o processo de trabalho e os textos produzidos no núcleo. Metodologia: Aulas coletivas com exercícios práticos e aulas expositivas; Workshops de criação dramatúrgicas; Leituras e reflexões sobre textos de conteúdos específicos (ver bibliografia); Apreciação e reflexão sobre filmes específicos que serão escolhidos de acordo com o processo; Apreciação e reflexão de espetáculos e eventos artísticos específicos; Discussões e avaliações constantes sobre o processo de trabalho. Conteúdo: Fundamentos do moderno e contemporâneo; O enredo e a personagem; Diálogos e rubricas poéticas; Conceito de pós-dramático e de drama estendido. ${ }^{3}$

É importante ressaltar que o núcleo adquire certas características e diretrizes devido à influência do mestre que está responsável pelo gerenciamento no momento. A dramaturga e diretora Solange Dias é mestre do núcleo de dramaturgia desde o segundo semestre de 2013. Dessa maneira, é possível perceber, por exemplo, um certo destaque para o pensamento teatral nomeado como pós-dramático, o que é coerente com a pesquisa que a mestre desenvolve artisticamente e academicamente.

Se isolarmos as idiossincrasias apontadas e analisarmos a descrição do núcleo de dramaturgia da ELT, veremos um arcabouço procedimental comum ao processo colaborativo. A preocupação desse tipo de abordagem metodológica, chamada aqui de dramaturgia colaborativa, no que se refere aos procedimentos essenciais, reside no tripé:

- Definições teóricas sobre o que seria dramaturgia na contemporaneidade.

- Prática de escrita individual, visando o fomento do universo ficcional de cada dramaturgo.

- E experimentação dos textos em cena.

Evidentemente, o caráter complementar que o núcleo de dramaturgia possui não impossibilitou que este contribuísse para a formação de diversos dramaturgos. Luís Alberto de Abreu, Antônio Rogério Toscano, Adélia Nicolete, Vadim Nikitin, Newton Moreno, Alessandro Toller, Roberto Alvim, entre outros, colaboraram, em algum momento de suas carreiras, para o projeto da ELT.

Apesar das recorrentes ameaças de fechamento, a ELT continua em atividade, assim como seu núcleo de dramaturgia. Espero que a escola resista por bastante tempo, de tal modo que o projeto se torne tão precioso para a cidade de Santo André a ponto de ser desvinculado do partido político responsável por sua criação. Seria a passagem de uma política cultural de governo para uma política cultural de Estado.

Para finalizar esta etapa, Vilma Campos dos Santos Leite expõe, na citação abaixo, os procedimentos experienciados por ela, quando foi aprendiz de Luís Alberto de Abreu, nos primórdios da Escola Livre de Teatro.

\footnotetext{
3 Disponível em: <http://www.escolalivredeteatro.blogspot.com.br/p/nucleos.html>. Acesso em: 28 mar.
} 
Iniciados os encontros, embora Abreu trouxesse à roda autores na base de sua formação como Aristóteles, Eric Bentley, Joseph Campbell, Mikhail Bakhtin, Jung e Walter Benjamin, era o processo de criação em Dramaturgia que estava no centro de qualquer discussão. Assim, por exemplo, o desenvolvimento de um tema como "imagem forte", ou "imagem quente", que é o que de humano "toca", apresentavase em consonância com a prática dos próprios participantes do núcleo"(Leite, 2010, p. 197).

A citação serve para fazer um contraponto com a descrição atual do núcleo de dramaturgia da ELT. Afora as possíveis diferenças referenciais entre Luís Alberto de Abreu e Solange Dias, o essencial é perceber a preocupação com as temáticas perseguidas pelos dramaturgos, que estas sejam urgentes e necessárias à contemporaneidade.

Referências

ABREU, Kil. Escola Livre de Teatro de Santo André. Jogar o jogo de olhos abertos. A Escola Livre e o teatro de grupo. Revista Subtexto. Belo Horizonte, n. 3, 2006.

ESCOLA LIVRE DE TEATRO. Reminiscências dos 20 anos da Escola Livre de Teatro por seus fazedores. Santo André, SP: Prefeitura de Santo André, 2010.

FAHRER, Lucienne Guedes. Luís Alberto de Abreu: a experiência pedagógica e os processos criativos na construção da dramaturgia. 2011. Dissertação (mestrado) - Universidade de São Paulo, Escola de Comunicações e Artes, São Paulo, SP.
LEITE, Vilma Campos dos Santos. Estações e trilhos da Escola Livre de Teatro (ELT) de Santo André (SP) 1990-2000. 2010. Tese (doutorado) - Universidade Federal de Uberlândia, Instituto de História, Uberlândia, MG.

TOSCANO, Antônio Rogério. A Escola Livre de Teatro (ELT) de Santo André... .Revista Subtexto. Belo Horizonte, n. 1, 2004.

Recebido em 12/12/2015 Aprovado em 25/05/2016 